\title{
Presentación
}

\section{Iris Marion Young, la pensadora de las injusticias estructurales y de la responsabilidad política*}

\author{
María José Guerra Palmero \\ Universidad de La Laguna. Instituto de Estudios de las Mujeres \\ mjguerrapalmero@gmail.com
}

En 2006, nos cayó como un jarro de agua helada la noticia de la muerte prematura de Iris Marion Young. Inmediatamente, tanto en la academia estadounidense como en los ámbitos transnacionales de la teoría política, y, muy especialmente, en la feminista, las necrológicas y los obituarios no dejaron de señalar la gran pérdida a la que nos enfrentábamos. Young había sido, en las últimas tres décadas, una de las pensadoras más incisivas y vanguardistas en su periplo filosófico y político, puesto que abordó un campo temático más que extenso y replanteó, bajo una nueva luz, numerosas cuestiones candentes relativas a la misma intelección de la política y de las teorías de la justicia. Fundamentalmente, afrontaba el hecho de cómo las opresiones cercenan las oportunidades y los derechos de las personas que pertenecen a los grupos, fuertemente estigmatizados, que las sufren. En su celebradísimo libro, publicado en 1990 por Princeton University Press, La justicia y la política de la diferencia, tras desvelar que el paradigma de la redistribución, clave en la teoría rawlsiana, ocultaba, al privilegiar sólo la desigualdad de clase, a las otras opresiones, ya indicaba que las diferencias de poder, la marginación en el ámbito de la toma de decisiones, el imperialismo cultural y la violencia eran

\footnotetext{
* Esta presentación, así como la labor de coordinación de este monográfico sobre la obra de Iris Marion Young, se inserta en el proyecto Justicia, ciudadanía y género: Feminización de las migraciones y derechos humanos (FFI2011-24210), financiado por el Ministerio de Economía y Competitividad del Gobierno de España. Los promotores del citado proyecto, en colaboración con el Departamento de Filosofía de la UAB, celebraron, en diciembre de 2012, un seminario sobre el libro póstumo de Iris Marion Young. Se celebró, también, una primera mesa sobre el pensamiento de esta autora en la XVI Semana de Ética y Filosofía Política. Congreso Internacional «Presente, pasado y futuro de la democracia», en abril de 2009. La publicación de la obra de Máriam Martínez-Bascuñán representa la primera obra de análisis crítico de la trayectoria de la autora en España. Se titula Género, emancipación y diferencia(s): La teoría política de Iris Marion Young, Madrid, Plaza y Valdés, 2012. Queremos recordar a Rafael del Águila, catedrático de Ciencia Política de la UAM, también, y desdichadamente, prematuramente fallecido, por haber alentado los estudios younguianos en España. Agradezco a Enrahonar, y especialmente a su directora, Marta Tafalla, que me hayan planteado el reto de articular este monográfico en torno a Iris Marion Young.
} 
aspectos decisivos a considerar por una teoría de la justicia que se precie. Las personas pertenecientes a grupos oprimidos que soportaban diversas dominaciones veían gravemente mermadas sus oportunidades y sus derechos. En consecuencia, con este hallazgo, Young afrontaba la tarea analítica de desbrozar los mecanismos por los cuales operan, se expresan y se reproducen las distintas opresiones, que muchas veces aparecen «interseccionadas» ${ }^{1}$. Uno de sus textos emblemáticos, titulado "Las cinco caras de la opresión»" ${ }^{2}$, nos ponía ya sobre la pista de considerar a Young como la pensadora de las injusticias estructurales. No sólo la clase, sino también el género, la raza o la etnicidad, la orientación sexual y la discapacidad van a ser las categorías que le posibiliten analizar las dinámicas de poder y opresión que funcionan, muchas veces, veladas y enmascaradas en las sociedades contemporáneas. Young es, además, plenamente consciente de partir de la experiencia política y reivindicativa de los llamados nuevos movimientos sociales, con el fin declarado de prestar su teoría política para la tarea de esclarecer los principios normativos y los procesos inclusivos que tienen que ponerse al servicio del desmantelamiento de las opresiones y del fortalecimiento de una democracia «real»y «radical».

Repolitizar una vida pública anestesiada por los efectos conformistas del Estado de bienestar y relanzar la teoría de la justicia más allá de la redistribución, pero conteniéndola, será uno de sus objetivos. Esto es, la democracia, entendida deliberativamente y con una radicalidad que desafía muchos de los presupuestos habermasianos, es presentada como una condición sine qua non de la justicia social. Tanto Intersecting Voices: Dilemmas of Gender, Political Philosophy and Policy (1997), también en Princeton University Press, como Inclusion and Democracy (2000), editado por Oxford University Press, aspiraron a desarrollar la intuición que ya despuntaba en el libro de 1990: el ideal de imparcialidad da cobertura al menosprecio y a la negación de las diferencias, y, como otras autoras ya habían detectado - por ejemplo: Seyla Benhabib, al hablar de la tácita antropología normativa que sostiene a las teorías de la justicia de Rawls y Habermas ${ }^{3}$-, encubre con su presunta neutralidad a los valores de los sectores sociales dominantes, que pasan, así, a ser desapercibidos. $\mathrm{El}$ respeto a las diferencias, que suelen estar vinculadas con desigualdades, y la reivindicación de un espacio público heterogéneo serán temas recurrentes en sus argumentaciones y desarrollos.

1. Está abierta la discusión de si considerar a Iris Marion Young como una teórica de la interseccionalidad. Su obra se desarrolla en paralelo y con sensibilidad hacia las propuestas de los feminismos negros, chicanos, lesbianos, etc. Para tener una visión general de este paradigma, véase H. Lutz, M. T. Herrera Vivar y L. Supik (eds.), Framing Intersectionality: Debates on a Multi-Faceted Concept in Gender Studies, Londres, Ashgate, 2011. He abordado el tema de la intersección de las opresiones en «Derechos humanos, intersección de opresiones y enfoques crítico-feministas», en C. Corredor y J. PEÑa (eds.), Derechos con Razón, Valladolid, Lex Nova, 2013, 49- 69.

2. En Iris M. Young, La justicia y la política de la diferencia, Cátedra, Madrid, 2000, 71-114.

3. He tratado este tema en "¿Tiene género la justicia?: Nota sobre el androcentrismo como tácita antropología normativa», en P. L. BLASCO (ed. y coord.), La justicia entre la moral y el derecho, Madrid, Trotta, 2013, 121-141. 
Curiosamente, la primera Iris Marion Young pudo profundizar adecuadamente en estas insidiosas dinámicas sociales, porque venía pertrechada con un valioso arsenal filosófico de categorías y metodologías analíticas. Sus inicios en el estudio de la filosofía continental están marcados por la lectura de la fenomenología. Destaca la atención a la corporalidad desarrollada por MerleauPonty, por la atención a los clásicos de la teoría crítica, como Adorno, pensador de lo negativo e impugnador de los moldes rígidos de la identidad, así como por el feminismo filosófico de Simone de Beauvoir, que le enseña cómo operan las constricciones sociales en la existencia vivida en femenino, así como por el de Luce Irigaray y Sandra Bartky, que le lleva a plantear la transvaloración de la experiencia del mundo de las mujeres. En 2005, completando con artículos posteriores a lo publicado en ediciones anteriores, en los que, por ejemplo, va a participar en la polémica entre las que oponen el «cuerpo vivido» al género, se compilan ensayos que cubren veinte años de su producción en los que Young nos brinda una teoría política del cuerpo feminista. Young despunta en lo que se ha denominado la cuestión del embodiment. Un artículo suyo titulado «Throwing like a girl: A Phenomenology of Feminine Body Comportment, Mobility and Spaciality», publicado ya en 1980 en Human Studies, uno de los que se han hecho más famosos, nos muestra cómo los condicionamientos sociales fuerzan a que las niñas interioricen su falta de potencia física y se muestren inseguras siguiendo el mandato insidioso de una feminidad hegemónica que las define como frágiles, delicadas y torpes. Lo anterior, interiorizado muy tempranamente y de manera arreflexiva como Habitus, por utilizar el concepto de Bourdieu, propicia un daño severo a su autoconfianza y autoestima. Los tabúes sobre la vida «íntima» de las mujeres son desvelados, asimismo, por Young, por ejemplo, al hablar de los significados sociales y simbólicos de la menstruación y de otras experiencias corporales sexuadas, para mostrar como la normalidad se ha construido con el referente falsamente neutro de la masculinidad dominante. La teoría de la corporalidad en su obra es una clave ineludible que actualiza el potencial feminista de pensar más allá de los límites impuestos por una tradición filosófica y política que ha pensado lo humano como razón incorpórea, dejando fuera a las mujeres y a otros grupos «marcados» corporalmente.

Tras llorar su pérdida personal y filosófica, el año 2011 trajo una sorpresa inesperada para los younguianos y las younguianas. Oxford University Press presentaba, con un imprescindible prólogo de Martha Nussbaum, en el que se narran los tira y afloja en torno a sacar a la luz una obra no preparada enteramente para su publicación, un libro póstumo de Iris Marion Young titulado Responsabilidad por la justicia. En esta ocasión, no hemos tenido, además, que esperar diez años para verlo traducido, en la editorial Morata, al español. La traducción, en este caso, salió inmediatamente, en el mismo 2011, tras la publicación del original en inglés. Algunos de sus capítulos y muchas de sus ideas habían sido adelantados en el libro que Young sí dejó preparado justo antes de su muerte y que salió, en 2007, en Polity Press, Global Challenges. War, Self-Determination and Responsability for Justice, pero la articulación de sus 
temáticas en el manuscrito póstumo resultaba muchísimo más esclarecedora. Young, en contraste con su crítica a la teoría de la justicia de Rawls, de finales de la década de 1980 y principios de la de 1990, va ahora a delimitar con claridad al «enemigo»: las teorías neoliberales que dinamitan lo público y que ensalzan únicamente la responsabilidad personal por el bienestar propio y familiar. Esas son las mismas visiones que ahora se tienen referentes a la crisis de la deuda europea, puesto que, sostienen, nos merecemos lo que está cayendo por «vivir por encima de nuestras posibilidades», por ello se aprestan a dinamitar a un ritmo vertiginoso los fundamentos del Estado del bienestar. Es verdad que uno de los vibrantes capítulos de La justicia y la política de la diferencia, titulado "La acción afirmativa y el mito del mérito» ya retrataba lo que, en la oleada neoliberal de las últimas dos décadas, no ha dejado de crecer: la defensa de la elitización que las clases hegemónicas persiguen intentando borrar todos los hándicaps de los que parten los miembros de los sectores desfavorecidos. El negar a éstos el acceso a la igualdad de oportunidades está en el núcleo duro de su mensaje, por más que quieran enmascararlo con el perverso discurso de la culpabilización de las víctimas de las injusticias estructurales: los pobres, las mujeres, los afroamericanos, los discapacitados, etc. Su ejemplo en el libro que comentamos: el de cómo margina y segrega, debido a sus reglamentaciones anónimas, el mercado inmobiliario, en Estados Unidos, a una madre soltera afectada por los bajos salarios y la precarización. La historia que narra Young, la de Sandy, es sumamente recomendable hoy en una situación como la española, en la que los desahucios, debidos a una infame ley hipotecaria que impide la dación en pago, están despojando y expoliando e, incluso, empujando al suicidio a los más vulnerables, a las víctimas de los duros «ajustes» organizados por los mercados internacionales, la irresponsabilidad de la banca y las presiones de las élites políticas europeas.

En este duro contexto de batalla política, que es el de avance imparable del neoliberalismo, de la desprotección social y del triunfo de las desigualdades, Young, además, va a traer a colación los nuevos retos que nos plantea el nudo de interacciones propiciado por la globalización. Su propuesta de un modelo de responsabilidad política como «conexión social» nos obliga a preguntarnos por «la historia de las cosas», por los orígenes de los productos que consumimos, uno de sus ejemplos va a ser la producción textil de las maquilas (swetshops) que luego venden a las grandes multinacionales del sector, como Zara y otras. Nuestra autora va a mostrar cómo los privilegios de los ciudadanos del Primer Mundo se sostienen en la explotación laboral y en el expolio de los recursos naturales de los países del Tercer Mundo. Young pretende politizar la globalización y desactivar, como Pogge y otros teóricos de la justicia global, el nacionalismo explicativo que carga a los habitantes de los países del Sur global con toda la responsabilidad por su «atraso». Se pretende, en suma, que tomemos conciencia de las interconexiones materiales y reales, además de cómo está distribuido el poder en la arena transnacional, dado que las corporaciones son los agentes decisivos de nuestro modelo económico. Más allá de un vacuo cosmopolitismo romantizado, que apela a meros principios universalistas des- 
carnados que, también, pueden tener el efecto de invisibilizar la alteridad, Young requiere de una ciencia social crítica que dé cuenta de lo que se intenta enmascarar y ocultar, de las desigualdades estructurales producidas por un sistema injusto. El luchar, en consecuencia, contra las injusticias estructurales globalmente articuladas, en sintonía en lo teórico con la propuesta de Nancy Fraser en Escalas de la Justicia $(2008)^{4}$, o en el terreno del activismo con los movimientos altermundistas, se propone al transformar el mismo concepto de responsabilidad, al colectivizarlo y singularizarlo a la vez, inspirándose en parte en Hannah Arendt, y al pretender que la responsabilidad política que se deriva de la conexión social mire y se proyecte hacia el futuro, hacia una transformación social y política global efectiva. Young, por último, nos previene contra las estrategias que eluden las responsabilidades y refutan sus argumentaciones.

Con el fin de proseguir con el esclarecimiento de los trabajos de Iris Marion Young, hemos convocado a especialistas en su obra que llevan analizándola críticamente desde hace tiempo, cuando Young aún vivía. Máriam MartínezBascuñán, profesora de Ciencia Política de la Universidad Autónoma de Madrid, nos ofrecerá, dado que ha trabajado arduamente en la comprensión y la crítica del pensamiento de Young, una visión sobre su trayectoria intelectual, en la que destacará el carácter netamente feminista de su apropiación de la política. Su artículo se titula «Iris Marion Young y la aproximación feminista de lo político: Un recorrido por su trayectoria» y nos sirve de pórtico y guía para orientarnos en la rica y diversa obra de la que fue profesora de la Universidad de Chicago, destacando sus hilos conductores. Lo político y la política es desbrozado por Young en diferentes fases, desde su crítica a la imparcialidad hasta su proposición de respeto a las diferencias y de acogimiento de la heterogeneidad como riqueza democrática. Los giros políticos de sus textos quedan resumidos por Máriam Martínez de la siguiente manera:

[...] Young pasa de la crítica a la reforma; de la cultura a la estructura; de problemáticas versadas en cuestiones sobre identidad, a reivindicaciones más estrictamente sociales; y de una preocupación, por último, centrada en la sociedad definida en términos de Estado-nación, a un análisis de lo que debe implicar la justicia dentro del ámbito global entrado en la noción de responsabilidad.

Se destacarán, así, las polémicas y las interpelaciones que ha recibido su obra en el contexto de debate estadounidense. Su desafío feminista a la escisión entre lo público y lo privado, su elaboración, de forma enormemente original, de una teoría política de la corporalidad y, finalmente, su insistencia en lograr una concepción de la justicia que opere contra las estructuras desiguales y que quede íntimamente ligada a la responsabilidad política en la era de la globalización serán los hitos de su recorrido.

4. Barcelona, Herder, 2008. Recomendamos, asimismo, la labor de edición, traducción al español y presentación de los textos de Nancy Fraser realizados por M. Antonia Carbonero y Joaquín Valdivielso en Dilemas de la justicia en el siglo Xxi: Género y globalización, Palma de Mallorca, Universitat de les Illes Balears, 2011. 
En segundo lugar, la catedrática de Filosofía de la Universidad de Valencia, Neus Campillo, esclarecerá «El significado de la crítica y de la responsabilidad política en Iris Marion Young». Destacará el engarce entre su enfoque fenomenológico, deudor de su formación especialmente en la filosofía francesa, con la tradición de la teoría crítica. Transitará por su teoría de la opresión y por su carácter multifacético para desembocar en la última Young y en su formulación de la responsabilidad política por la justicia, atendiendo tanto a destacar la intelección de lo estructural como la experiencia que los sujetos viven en tales asimetrías sociales. Al detenerse en la denuncia que hace Young de las falaces argumentaciones que se esgrimen para eludir la responsabilidad, Neus Campillo nos hace ver el papel del análisis fenomenólogico en su análisis, así como, inspirada en Derrida, la reivindicación de la amistad política ligada al responder ante los otros concretos, ante una alteridad que interpela en los términos establecidos por Lévinas. Tal respuesta está modulada por parámetros de razonamiento moral — poder, privilegios, interés y capacidad colectiva — que nos ayudarán a calibrar nuestras intervenciones en las luchas contra las injusticias estructurales. Neus Campillo nos ayuda decididamente a entender el entramado filosófico que sostiene la obra política de Young.

En tercer lugar, Cristina Sánchez, profesora titular de Filosofía del Derecho, de la Universidad Autónoma de Madrid, sopesará, en «Responsabilidades globales e injusticias estructurales: una lectura de Iris Marion Young», la discusión de esta autora con la teorización de la culpa y la responsabilidad elaborada por Hannah Arendt. Cristina Sánchez trabajará las distinciones categoriales implicadas con una gran precisión, con el fin de esclarecer los sentidos de la responsabilidad ligados a cómo enfrentar los efectos del mal banal, los daños producidos arreflexivamente por seguir las perversas inercias sistémicas. Esta tarea de repensar la responsabilidad colectiva, y su carácter netamente político, se sitúa ante el reto de ser relevante en los actuales términos delimitados por el proceso imparable de la globalización. La aportación de Young, por tanto, se enmar$\mathrm{ca}$, a este respecto, en los términos de las teorías de la justicia global.

En cuarto lugar, Martha Palacio Avendaño, investigadora de la Universidad de Barcelona, ha analizado el debate entre Iris Marion Young y Nancy Fraser en torno a la estructura de la justicia. Sus intercambios polémicos en la década de 1990 son su objeto de estudio. Muestra, así, las preocupaciones comunes de ambas autoras y sus afinidades teóricas, pero, también, plantea la confrontación entre el modelo bifronte — redistribución y reconocimiento, en los últimos tiempos se le ha sumado la representación política- de la justicia en Nancy Fraser y la conceptualización de la opresión, que no es unitaria, sino dinámica y polifacética, de Young. Ambas autoras responden a las demandas de los movimientos sociales y al acicate feminista por repensar lo político, y ambas pretenden superar el marco rawlsiano y radicalizar el referente deliberativo de la democracia que ha sido planteado por Habermas. Sin embargo, uno de los puntos calientes de su debate será cómo se debe tratar con las diferencias. Fraser acusa a Young de fortalecerlas incluso en contra de su objetivo de luchar contra las injusticias estructurales y aboga por políticas transforma- 
tivas. El modelo de Fraser es acusado de reduccionista, en cambio, por Young. Las tensiones entre lo económico y lo cultural y las distintas formas de conceptualizarlas en el marco de una justicia global son elementos de esta polémica. Lo que no se puede olvidar es la necesidad de democratizar los marcos políticos emergentes en la globalización y que, ahora, son frenados violentamente por los mecanismos del capitalismo financiero. Estos son algunos de los puntos de fuga de este debate inacabado debido a la prematura desaparición de Young que Martha Palacio Avendaño nos invita a repensar.

En quinto lugar, Lucía Acosta Martín, investigadora de la Universidad de La Laguna, aborda, en torno a las categorías de género y cuerpo vivido, la evolución del pensamiento de Young respecto a la opresión sexista, esto es, desde los años ochenta hasta la pasada década, y la contrapone con la visión de la corporalidad, como sede de la dominación, de Pierre Bourdieu. Tal contraste le permite estimar los logros analíticos de la que fue profesora de la Universidad de Chicago respecto a cómo la feminidad, y sus constreñimientos, oprime y despotencia a las niñas y a las mujeres. La conjunción de opresión incorporada, internalizada, y la serialización discriminatoria en la estructura social devalúa la experiencia social de las mujeres. El género, no obstante, es una categoría imprescindible, a decir de Young, para dar cuenta de la injusticia estructural más ubicua y resistente, la que opera contra las mujeres.

En sexto lugar, contamos con la crítica que Ann Ferguson, profesora emérita de la Universidad de Massachusetts en Amherst, colega y amiga de Young, elabora de su última teorización sobre la responsabilidad por la justicia. Ferguson complementará el modelo de Young con su propuesta de la justicia como solidaridad. No una solidaridad meramente cosmopolita y abstracta, sino empíricamente revelada como redes de ayuda y cooperación transnacionales que han surgido frente a las agresiones de la globalización neoliberal a los más empobrecidos, especialmente a las mujeres humildes que afrontan los retos de la feminización de la pobreza y de la supervivencia. Ferguson atiende a la interseccionalidad de las opresiones como terreno donde articular solidaridades feministas, pero, también, a la economía solidaria emergente — especialmente, nos brinda ejemplos de Latinoamérica y de lazos políticos con iniciativas estadounidenses ligadas al comercio justo y a la colaboración transnacional-, como fundamentos de la solidaridad global. Repensar, al hilo de la justicia global, las redes encarnadas de solidaridad es el reto que se plantea para sustentar las posibilidades de lucha política contra un capitalismo depredador que o bien explota brutalmente o bien declara superflua a gran parte de la población mundial.

Para cerrar este número, contamos con otras contribuciones más breves. Oriol Farrés Juste nos ofrece su visión del tratamiento que Young da de la injusticia histórica y de cómo afrontarla desde la responsabilidad política. A continuación, Ángela Lorena Fuster Peirò nos ofrece una interesantísima nota crítica sobre los apasionantes Diarios de Hannah Arendt, autora decisiva en influenciar a la última Young respecto a su concepción de la responsabilidad. Finalmente, Arnau Matas Morell nos reseña el libro de Joaquín Valdivielso 
titulado Ciudadanos, naturalmente: Reciclar los valores cívicos en clave ecológica, en el que se plantea la absolutamente necesaria cuestión de la ciudadanía verde, y Lambra Saínz Vidal comenta el trabajo de Michael Reder titulado Globalización y filosofia, que obedece, también, a la necesidad de reenmarcar nuestras teorías en nuevas coordenadas planetarias.

El lector o la lectora que no se haya acercado aún a la obra de Iris Marion Young no quedará defraudado cuando se adentre en ella. Una obra no suficientemente conocida aún ni en España ni en Iberoamérica. Encontrará vibrantes y desafiantes las reflexiones y las conceptualizaciones de la tristemente fallecida profesora de Chicago. Su teoría política es esencial para entender las fuertes tensiones económicas, sociales y políticas que asolan a nuestro presente nacional y transnacional. Por último, encontrará que la propuesta de la responsabilidad política colectiva que nos plantea Young, sobre todo en su última obra, colaborará a forjar la esperanza de revertir las fuerzas globales desatadas contra la igualdad y la justicia. 